\title{
Immunological aspects of persistent hepatitis B in children
}

\author{
Harsoyo Notoatmojo \\ Department of Child Health, Medical Faculty, Diponegoro University - Dr. Kariadi General Hospital Semarang
}

\begin{abstract}
We studied the immunological status of 203 children having persistence Hepatitis B (positive HBsAg) ranging in age from 6 to 14 years in Semarang Municipality. The results of humoral immunity examination (IgM Anti-HBc) showed that all were negative, indicating that they are not in acute phase of hepatitis B infection. Cellular immunity examination, i.e., CMI skin test has shown positive result in $64.9 \%$ on persistent and $65.2 \%$ in non persistent hepatitis $B(p>0.05)$. T cell examination showed statistically significant difference $(p<0.01)$ between persistenct and non persistent hepatitis $B$ patients, there was is also significant difference $(p<0.01)$ on CD4 cell examination. These findings indicated that there was difference in immunoregulation function and response repression of antivirus between both groups of patients. On the other hand CD4/ CD8 ratio and $T$ cell function showed no significant difference between the two gorups of patients; similarly the specific function of cytotoxic $T$ cell was not significantly difference. [Paediatr Indones 2001; 41:208-213]
\end{abstract}

Keywords: persitent hepatitis-B, humoral immunity, immunoregulation, children

STUdies HAVE SHOWN THAT HEPATITIS B VIRUS (HBV) is not a cytopathic virus against liver cells. This can be seen in healthy carriers, that although there are lots of HBV particles in the liver cells, there is no pathological disorder in the liver tissues. The HBV infection is caused mainly by the immunological reaction of the carrier's against the liver cells infected by HBV. ${ }^{1,2}$

The clinical manifestations of the infection depend very much on its immunological reaction, particularly the cellular immunological reaction against $\mathrm{HBV}$. If there is none or only minimum immunological reaction, the carrier will be healthy. Acute $\mathrm{B}$ hepatitis will occur if the immunological reaction causes liver cell necrosis followed by the disappearance of HBV from the liver cells. When the immunological reaction

Correspondence: N. Harsoyo, M.D.,Department of Child Health, Medical Faculty, Diponegoro University - Dr. Kariadi General Hospital Semarang, Indonesia. does not succeed to destroy HBV from the liver cells, there will be a chronic hepatitis. When the necrosis on the chronic B hepatitis is wide, it will become aggressive chronic, and if there is only little necrosis, there will be persistent chronic B hepatitis. ${ }^{3-5}$ This paper reports our study on humoral and cellular responses of persistent infection of HBV will be discussed.

\section{Methods}

The random sampling took children of 6-14 years old in Semarang Municipality. In perspective, there were children with persistent and non persistent hepatitis B. The research planning used perspective method for finding the persistent of $\mathrm{HBV}$ as a subject. The immunological factors examined were humoral immunity in the form of IgM anti-HBc, and Anti HBs. There was no anti-HBe nor anti-Pre S1 neither Pre S2 examination conducted. The cellular immunity examined was the total number of lymphocyte cells, CMI skin test, the number of $\mathrm{T}$ cells, $\mathrm{T}$ helper and $\mathrm{T}$ suppressor, as well as the CD4/CD8 cell ratio. 
The immunological variables consisted of variables of skin test, T rosette cell, CD4 cell, CD8, ratio of CD4/CD8 and specific function of $\mathrm{T}$ cytotoxic cell. The skin test variable was the skin test using CMI multitest from Paris and it is called positive if in $2 \times 24$ hours the diameter of indurations is $>2 \mathrm{~mm}$. The $\mathrm{T}$ cell variable was the $\mathrm{T}$ cell in rosette form and was examined by using $\mathrm{T}$ rosette method. The variable of CD4 cell is T helper cell examined by using ELISA in \% unit. The variable of CD8 cell was T suppressor cell or T cytotoxic cell which was examined by using ELISA in $\%$ unit. The variable function of cytotoxic cell was $\mathrm{T}$ cytotoxic cell examined by MIF method.

The analysis between the risk factors and the persistent HBV used the controlled study method. The statistical analysis was conducted by using $t$ test and Chi-square.

\section{Results}

IgM Anti $\mathrm{HBc}$ examination was administered to 203 children having positive $\mathrm{HBs} \mathrm{Ag}$, and it turned out that all children show negative IgM Anti-HBc. In this research, there was not much symptom on children having positive $\mathrm{HBsAg}$, or in other words these children were $\mathrm{HBsAg}$ asymptomatic carriers. Also, when their blood was taken for the test, none of them was having acute HBV infection. The IgM anti $\mathrm{HBc}$ examination was conducted to differentiate acute hepatitis and chronic hepatitis. ${ }^{(6)}$ Brunetto et al. (1993) stated that IgM anti-HBc was useful for diagnosis and supervision of chronic hepatitis $\mathrm{B} .{ }^{(7)}$

The result of the examination of cellular immunity response included the result of a) CMI skin test, b) T lymphocyte cell, c) CD4 cell, d) CD8 cell, e) ratio of CD4/CD8 and $\mathrm{f}$ ) specific function of cytotoxic $\mathrm{T}$ cell against pure $\mathrm{HBs} \mathrm{Ag}$.

\section{Skin Test}

Table 1 shows the relationship of CMI skin test and persistent HBV infection on children.

TABLE 1. RELATIONSHIP OF SKIN TEST AND PERSISTENT HBV INFECTION

\begin{tabular}{|c|c|c|c|c|c|}
\hline \multirow[t]{3}{*}{ CMI SkinTest } & \multicolumn{4}{|c|}{ HBV Infection } & \multirow{3}{*}{$\begin{array}{l}\text { Total } \\
\mathrm{n}\end{array}$} \\
\hline & \multicolumn{2}{|c|}{ Persistent } & \multicolumn{2}{|c|}{ Nonpersistent } & \\
\hline & $\mathrm{n}$ & $\%$ & $\mathrm{n}$ & $\%$ & \\
\hline Negative 40 & 35.1 & 31 & 34.8 & 71 & 35 \\
\hline Positive 74 & 64.9 & 58 & 65.2 & 132 & 65 \\
\hline Total & 56.2 & 89 & 43.8 & 203 & 100 \\
\hline
\end{tabular}

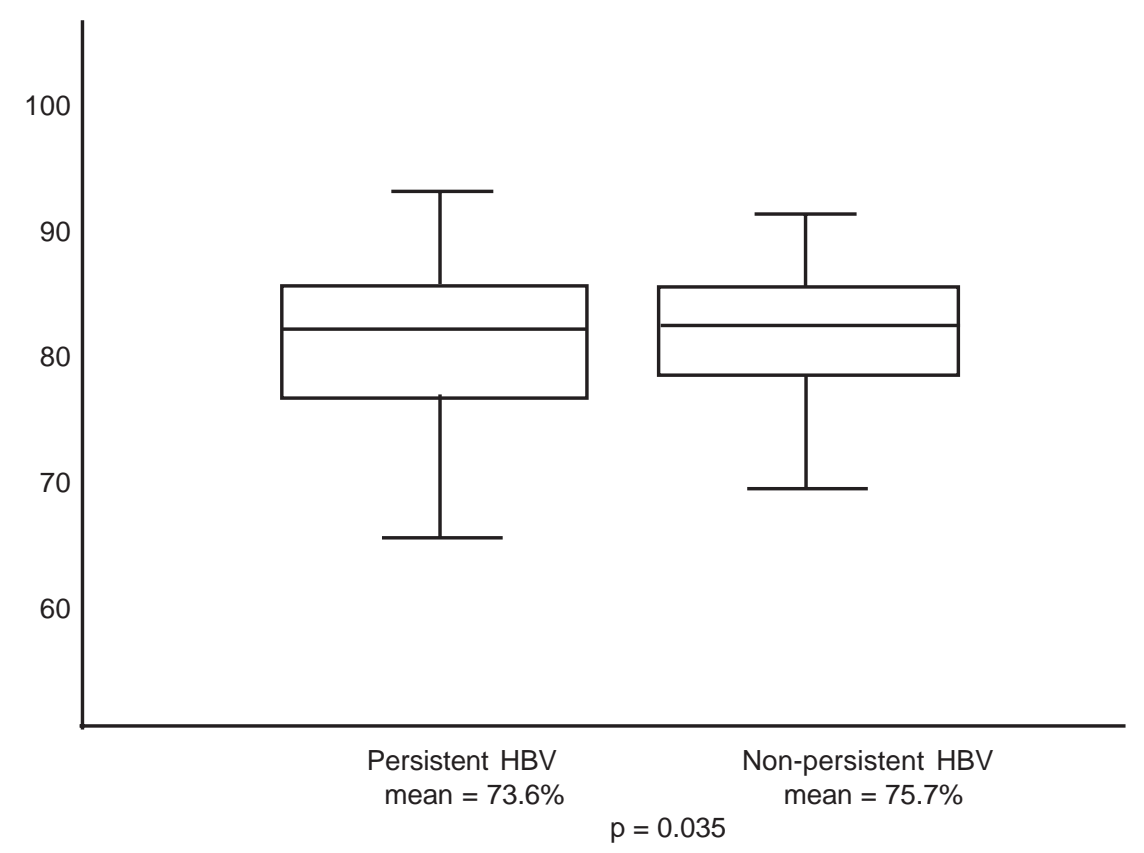

Figure 1. T Lymphocyte cell on persistent HBV infection and non persistent ones. 


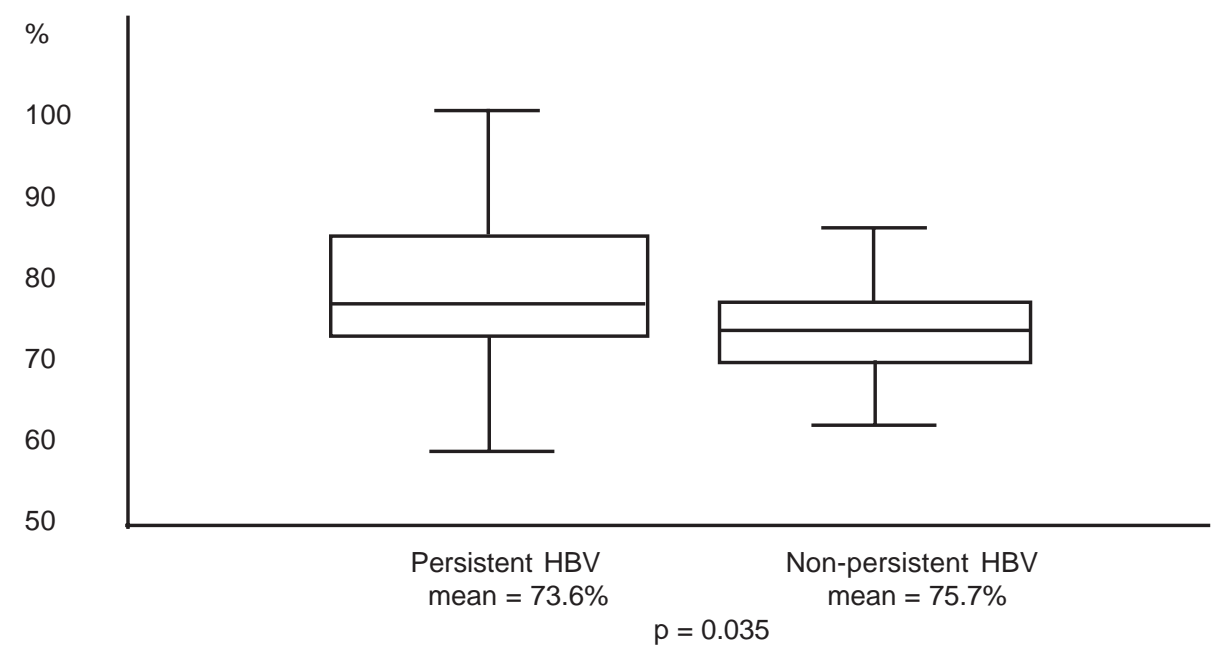

Figure 2. Number of CD4 cells on persistent and non persistent HBV infection on children

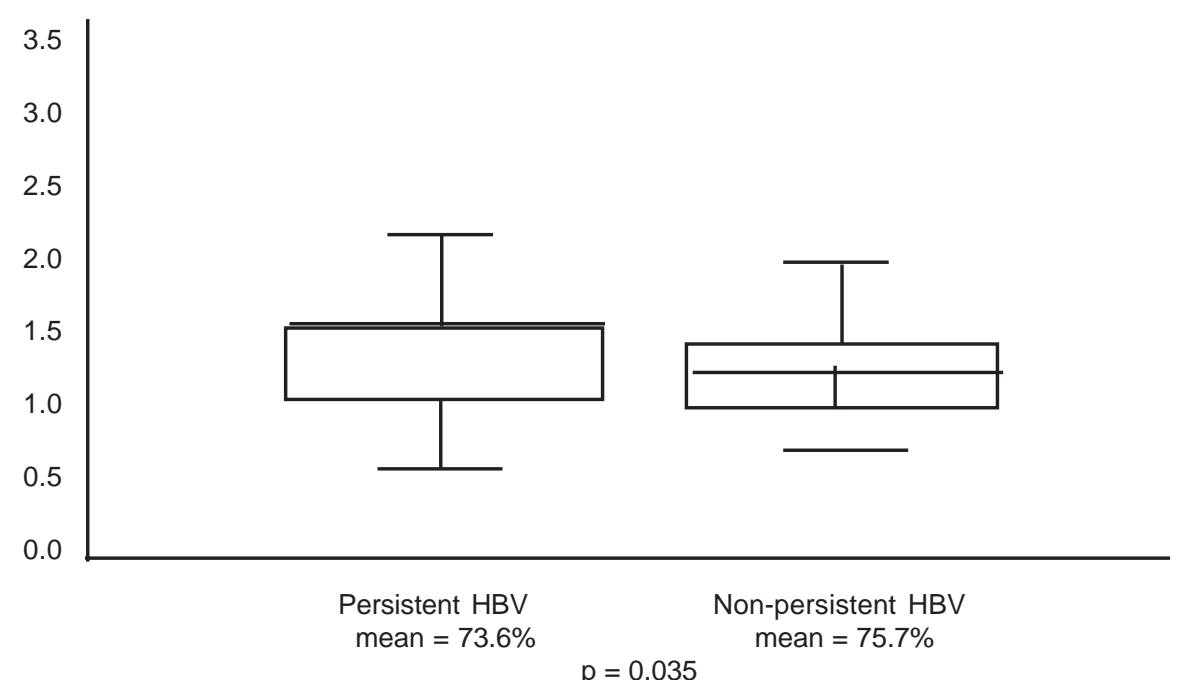

Figure 3. The total average of CD8 cells on persistent and non persistent HBV infection on children.

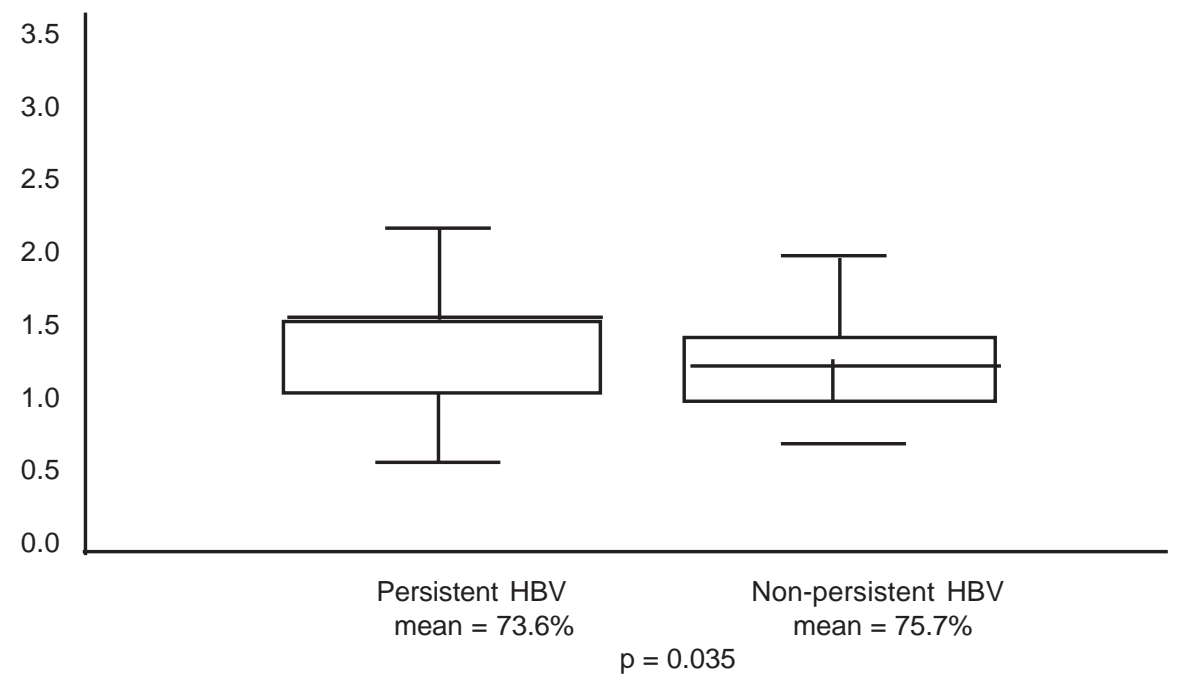

Figure 4. The average of CD4/CD8 ratio on persistent and non persistent HBV infection on children. 


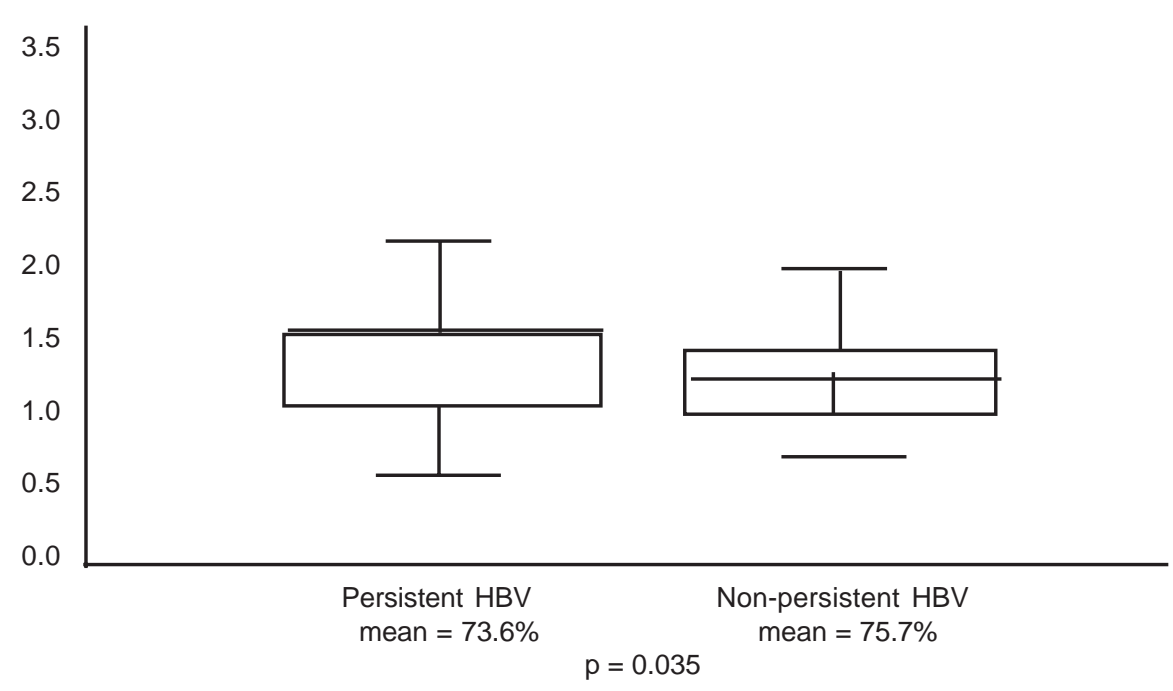

Figure 5. The function of specific T cell on persistent and non persistent HBV infection on children.

Table 1 shows that out of 203 children having skin test, 71 children (35\%) were negative and 132 (65\%) were positive. Positive skin test on persistent children was $64.9 \%$ and on non persistent $65.2 \%$, while negative skin test on persistent ones was $35.1 \%$ and on non persistent ones is $34.8 \%$. By statistical analysis chi square, there was no significant relationship between skin test and HBV infection on persistent children $(\mathrm{p}>0.05)$.

\section{T Lymphocyte Cell}

Figure 1 shows some difference on average number of T lymphocyte cell of persistent HBV infected children and the non persistent ones. Figure 1 shows that the average number of $\mathrm{T}$ cells on persistent HBV infection was less than the non persistent ones and statistically significant $(p<0.05)$. This shows that if the T lymphocyte cell was increasing, then the cellular immunity response function would be more active, so that the increasing $\mathrm{T}$ lymphocyte cell would cause the HBsAg destroyed and disappeared. This research shows that the number of $\mathrm{T}$ lymphocyte cell was decreasing, meaning that the cell number for cellular immunity was also decreasing, so that the percentage of persistent was increasing.

\section{T Helper Cell or CD4 Cell}

The difference between CD4 cell on HBV on persistent and non persistent children can be seen on Figure 2.
Figure 2 shows that there was a difference on average number of CD4 cells on persistent and non persistent HBV infection on children $(\mathrm{p}<0.001)$. Total number of CD4 cells on persistent ones were higher than the non persistent ones, this indicated that if CD4 cells was increasing, the persistency was also increasing. This was due to that the CD4 cells has a function to regulate the immunoregulation or even suppress the anti virus response. ${ }^{(8)}$

\section{T Cytotoxic Cell (CD8 Cell)}

The difference of total average of CD8 cells on persistent and non persistent HBV infection on children can be seen in Figure 3. Figure 3 shows that there was no significant difference between the total number of CD8 cells on persistent and non persistent HBV infection on children $(p>0.05)$. If has been known that the $\mathrm{T}$ cytotoxic cell has a very important role in the damage of liver cells on hepatitis B.

\section{Ratio of CD4/CD8}

Figure 4 shows the difference between the ratio of CD4/ CD8 and the persistent and non persistent HBV infection on children. Figure 4 shows that there was no significant difference between the average of CD4/ CD8 ratio and the persistent and non persistent HBV infection on children $(p>0,05)$. If the CD4/CD8 ratio is more than 1 , it will cause the infection to be persistent, and if it is less than 1, it will decrease the persistency. 
This is because the number of T cytotoxic cells will be increasing and the CD4/CD8 ratio becomes less than 1. In this case, the $\mathrm{CD} 4 / \mathrm{CD} 8$ ratio has no relationship with the HBV infection persistency.

\section{The Function of Specific T Cell}

The difference between specific $\mathrm{T}$ cytotoxic cell function and persistent and non persistent HBV infection on children is shown on Figure 5. Figure 5 shows that there was no significant difference between the function of specific $\mathrm{T}$ cell on persistent and non persistent HBV infection on children ( $p>0.05)$. Migration inhibition factor (MIF) test is conducted by using pure $\mathrm{HBs} \mathrm{Ag}$ as the antigen. From this test, there was no difference observed between the group of children having persistent and non persistent infection.

\section{Discussion}

There are two things required to cure HBV infection, i.e.: The first is the cellular immune response which is effective to destroy the infected liver cells. The second is the humoral neutralizing antibody which can prevent the spreading of the virus which flee into the other liver cells which are still healthy. When there is any disturbance in either one or both the two mechanisms above, the infection will become persistent. ${ }^{(5)}$

It has been known that there are several important antigen systems against the HBV infection, namely: $\mathrm{HBs} \mathrm{Ag}, \mathrm{HBcAg}$ and $\mathrm{HBeAg}$, and these three antigen will cause humoral immunity response of the body, namely Anti-HBs, Anti-HBc and Anti-HBe. However, the result of the research shows that the persistent group had no Anti-HBs formed yet and all the groups had negative Anti-HBc, so that they could not be differentiated statistically.

Anti pre S1 and anti pre S2 were not examined, and latter it is known that HBsAg consists of S, pre S1, and pre S2 components, which will form anti S or anti HBs, anti pre S1 and anti pre S2. Research conducted by Neurath et al (9) shows that the immunodominant epitope of HBsAg is located in protein pre-S, and in pre $\mathrm{S} 2$ to be precise. It has been proofed that the binding site of HBsAg is located in pre-S2. ${ }^{(9)}$ In the recovery process of acute hepatitis $B$, before the anti-HBs appears, the first one appears is anti pre-S2. Some researches show that both on acute and chronic hepatitis, pre-S2 is the indicator of the
HBV disappearance or the recovery from HBV infection. Anti pre-S2 is not found on acute hepatitis B which tends to be chronic, and is not found on chronic hepatitis B. ${ }^{(1)}$

Research shows that Anti-pre $S$ is the neutralizing antibody released during HBV infection. Anti-pre $\mathrm{S}$ has the role as the starter in the recovery process of HBV infection. This antibody is the first antibody in the recovery stage. And the titer of Anti-pre $S$ was decreasing along with the disappearance of HBsAg. ${ }^{(1,5)}$

The result of the cellular immunity examination was that the CMI skin test shown no significant difference. The negative result of skin test on persistent $\mathrm{HBsAg}$ shows that on persistent $\mathrm{HBsAg}$ of $35.1 \%$, the cellular immunity is generally low. This condition is caused by various situations, the growth of the immature immune cells, the status of nutrition, calory and protein or other vitamin. This is also stated by Stites (1991) that chronic infection will cause the decrease of cellular immunity. ${ }^{(10)}$ Lack of calory and protein also decreases the cellular immunity. ${ }^{(11)}$

The conclusion is that the T lymphocyte cell has the role as the risk factor of persistent HBV infection on children. This is the same as the research conducted by Dinfeng et al (1980) which found out that the $\mathrm{T}$ cell is decreasing on all hepatitis groups examined, particularly on fulminant hepatitis and active chronic hepatitis, which cause the recovery percentage is decreasing and becomes persistent. ${ }^{(12)}$

Figures 1 and 2 show the total number of $\mathrm{T}$ cells and CD4 cells on persistent and non persistent HBV which are different significantly in statistic $(p<0.01)$. This shows that total number of $\mathrm{T}$ cell in general on persistent hepatitis $B$ is less than the non persistent ones, so that the function to eliminate the virus is also lessening, the CD4 cells show that the immunoregulation function and immune response repression is still enough and different between the persistent and non persistent ones.

In this research, the specific $\mathrm{T}$ cytolytic cell function against $\mathrm{HBs} \mathrm{Ag}$ has no significant difference $(p>0.05)$. This is probably due to the antigen used for the MIF test is pure HBsAg, but does not use $\mathrm{HBcAg}$, since in persistent hepatitis, the target antigen is $\mathrm{HBcAg}$ or HBeAg. If the MIF test is normal, this means that the $T$ cell function is good and there is no liver cells damage. The damage of liver cells is caused by immunological response against the liver 
cells infected by HBV which cause the target antigen appears on the cell membrane. ${ }^{(12,13)}$ On acute hepatitis, the target antigen is HBsAg. ${ }^{(14)}$ In this case, the one having the important role is the $\mathrm{T}$ cytolytic cell which is capable of identifying the HBV antigen created on the cell membrane. ${ }^{(15)}$ Dienstag (1984) found that the liver cells damage was caused by the effort of the body to eliminate the HBV. ${ }^{(13)}$ This is influenced by several factors such as the existence of anti $\mathrm{HBc}$ in the circulation, imunoregulator in the serum, and the role of HLA class I. The T cytolytic cell can identify the target antigen, if the target antigen is created and appears along with the HLA class I. On chronic hepatitis $\mathrm{B}$, it is often that there is no HLA class I on the cell membrane, so that the immune cellular system can not touch the cells infected by HBV, which creates HBV antigen on the cell surface. ${ }^{(14)}$ It is understandable that the individuals on this research are children having persistent HBV infection whose MIF test is normal, since actually the cellular immune response against the HBV particle in vitro is probably still normal, while if it is in vivo, the result could be different. Besides, on chronic HBV infection, the target antigen created on the cell membrane is $\mathrm{HBcAg}$ or $\mathrm{HBeAg}$, and not $\mathrm{HBsAg}$.

The conclusion of this research about the immunological aspect of persistent HBV as follows. The result of humoral immunity examination in this research of Ig Anti-HBc has been all negative.

Cellular immunity examination in this research such as CMI skin test is not significant difference ( $p>0.05$ ), $T$ cell examination show significant statistically difference $(p<0.01)$, CD4 examination also significant different $(p<0.01), C D 8, C D 4 / C D 8$ ratio and the specific function of cytotoxic $\mathrm{T}$ cell show no significant difference $(\mathrm{p}>0.05)$.

\section{References}

1. Alberti A, Cavalletto D, Pontiso P, Chemello L, Tagariello G, Belussi F. Antibody Response to Pre-S2 and Hepatitis B Induced Liver Damage. Lancet 1988; 1:1421 23.

2. Alberti SA, Diana S, Eddleston ALWF, Scullard GH. Detection of a new antibody system reacting with Dane particles in hepatitis B virus infection. BMJ 1978; 2:1056-58.
3. Dientag JL. Immunologic mechanism in chronic viral hepatitis. In: Vyas GN, Dientag JL, Hoofnagle J, editors. Viral Hepatitis and Liver Disease. New York: Grune and Stratton Inc., 1984;135-164.

4. Eddleston ALWF, Mondelli M, Mieli-Vergan IG, Alpert A. et al. Lymphocytes cytotoxicity to autologous hepatocytes in chronic hepatitis B virus infection. Hepatology 1982;2:122S-127S.

5. Eddleston ALWF. Immunological aspects of hepatitis B infection. In: Zuckerman A, Allan R, editors. Viral hepatitis and liver diseases. New York: Liss Inc., 1988;603-605.

6. Kiyosawa K, Wada S, Imai Y, et al. Significance of IgM antibody to hepatitis $\mathrm{B}$ core antigen for the differential diagnosis of acute and chronic hepatitis $B$ virus infection and for the evaluation of the inflammatory activity of type $B$ chronic liver diseases. Gastroenterology Japonica 1986;21:6.

7. Brunetto MR, Cerenzia MT, Oliveri F, et al. Monitoring the natural caurse and response to therapy of chronic hepatitis B with an automated semi-quantitative assay for IgM anti-HBc. J. Hepatol 1993;19:431-436.

8. Barnaba W, Musca A, Cordova C, Levrero M, Ruocco G, Balsanof. Relationship betwee n T cell subsets and supressor cell activity in chronic hepatitis B virus infection. Clin. Exp. Immunol.1983;53:281-288.

9. Neurath AR., Kent S.B.H., Strick N. The biological role of pre-S sequences in the hepatitis B virus envelope protein : Implication for vaccine design. Proceeding of Asian symposium on strategies for large scale Hepatitis B immunization. Hong Kong June 12-13, 1986;97-112.

10. Stites DP and Terr AI. Basic and clinical immunology. Prentice-Hall Intern. Inc. USA. 1991.

11. Dienfeng Z, Bangyuan L, Zuchong L and Fengsheng C. Cell-mediated immune response in viral hepatitis B. Chinese Med. J 1980;2:90-97.

12. Dienstag JL. Immunologic mechanism in chronic viral hepatitis. In: Vyas GN, Dientag JL, Hoofnagle JH, editors. Viral hepatitis and liver disease. New York: Grune \& Stratton Inc., 1984.

13. Eddleston ALEF. Overview of HBV pathogenesis. In: Hollinger FB, Lemon SM, Margolis H, editors. Viral hepatitis and liver disease. Baltimore: Williams \& Wilkins, 1990.

14. Aoyama K, Kojima T, Inoue K, Sasaki H. Immunohistochemical investigation of hepatitis $B$ virus associated antigens, HLA antigens and lymphocyte subsets in type B chronic hepatitis. Gastroenterologia Japonica 1990;25:41-53.

15. Mondelli M, Vergai GM, Alberti A, et al. Specificity of $\mathrm{T}$ lymphocyte cytotoxicity to autologous hepatocytes in chronic hepatitis $B$ virus infection : evidence that $T$ cells are directed against HBV core antigen expressed on hepatocytes. J. Immun. 1982;129:6. 